\title{
Joaquim Cardozo, crivo e deserto
}

\section{Manoel Ricardo de Lima*}

\section{Resumo:}

O artigo apresenta o procedimento de Joaquim Cardozo com o poema através de uma idéia da linguagem como imagem desviante, aberta, a partir da imagem do crivo, para cumprir o seu próprio deserto. $\mathrm{O}$ artigo parte do pensamento crítico de Joaquim Cardozo e de um poema seu intitulado Prelúdio e Elegia de uma Despedida, publicado pela primeira vez em 1952, num livro chamado TRIVIUM, para verificar as relações de sua poesia com esta questão.

\section{Palavras-chave:}

Poema, deserto, espaço, experiência, Joaquim Cardozo

No trem, pelo deserto

Mário Faustino

\section{Um}

Joaquim Cardozo diz numa entrevista de 1971, comentando sobre as possibilidades gráficas de se compor um poema, que tinha alguns poemas que se desenhavam como árvores, árvores lógicas, tecidos, favos, crivos etc. Diz que partia de uma palavra, abria ramos nela e provocava a leitura da esquerda para a direita, de baixo para cima, da direita para a esquerda, de cima para baixo; diz também que isto era "um fenômeno a que já aludi, quando surgiu o Concretismo". Que, com isso, acreditava apresentar, então, "a possibilidade de se ler um poema como se vê uma pintura: não se pode vê-la toda de uma vez. Ela é percorrida pela vista e assim a pessoa pode seguir para a direita, para a esquerda, percorrê-la em todos os sentidos." Acrescenta dizendo que um poema pode ser feito assim, "usando-se árvore ou tecidos" e que "nos tecidos como nas árvores, a leitura não é linear. Há outras maneiras, como crivos ou grafos. Os grafos poderão ser como uma rede de linhas ligadas por pontos ou nós." O fato é que Joaquim Cardozo aponta para um devir do poema como uma preocupação a uma outra proposição do espaço, outra concepção de pensamento do espaço, através de uma idéia do deserto, que se engendra no tempo, como um crivo que coloca em jogo o destino dos homens no mundo, pelo deserto. O deserto como um espaço intensivo de distâncias e sem medidas, o Spatium intenso em vez de Extensio - como uma paisagem íntima de afecções para interromper a catástrofe, para interromper a história.

O crivo, a que se refere Joaquim Cardozo, é o que recupera a imagem de uma peneira, ou de um escoador, daquilo que vaza pelos furos. Um dos maiores

\footnotetext{
* Doutor em Literatura UFSC.
} 
impasses do poema de Joaquim Cardozo é armar um ponto furo na imagem. $E$ isto tem a ver diretamente com a imagem do crivo, que é uma espécie de labirinto; ou seja, um espaço informal, aberto, contingente, como aquilo que ocupa o espaço liso, como as intensidades, os ventos e ruídos, as forças e as qualidades tácteis e sonoras que, por exemplo, atravessam um deserto, como superfície, como território íntimo e como lugar sem. O crivo tem a ver também com o labirinto das rendas que são feitas no Agreste, em quase todo o Nordeste, porque os principais fios usados na produção deste artesanato das rendeiras são provenientes do algodão, e as peças são feitas a partir do fio que é trançado no labirinto ou no crivo, o fio precisa vazar o tecido para ser visto. Com o tempo, as rendeiras que trabalham com o labirinto, são acometidas de cegueira devido ao branco alucinatório do tecido e desse movimento repetitivo dos fios que escoam. Assim, a partir do crivo, ao comentar uma retrospectiva de Goeldi, no MAM do Rio de Janeiro, em 1958 (Para Todos: Rio de Janeiro, São Paulo, v. 1, n. 11, p. 9, 2a quinz. out. 1956), Joaquim Cardozo diz que reconhece o esforço de alguns que buscam reformar a gravura, que não se coloca como os que detestam as gravuras à feição de Jean Michel Papillon ou Thomas Bewich - de fins do século XIX - nem muito menos dos que negam todo o merecimento ao Holzstich, ou seja, dos que são contra o uso de madeira dura (que precisa ser tratada pelo buril) e a favor de uma mais branda e fácil de cortar; mas isto é apenas para dizer que compreende a importância de um impulso generoso para uma nova espacialidade: "reconheço nesta as qualidades originais de uma 'espacialidade' que não existia nas gravuras de época anteriores", muito por causa do uso do "cunho, o sinete da matéria: a reprodução das próprias linhas e nervuras da madeira, certos amortecimentos e turvações de colorido, motivados pela complacência das células vegetais". Estas turvações, para Joaquim Cardozo, comparecem nas gravuras de Goeldi, por exemplo, de uma maneira que interessa particularmente ao seu poema, como "se na atmosfera pairasse uma névoa seca, envolvendo, abrumando o espaço, e tornando as cores mais amortecidas, em virtude do deslocamento das raias do espectro luminoso". Em diante, aponta para uma impressão que vem provocada como segredo, o que ele diz ser o segredo dos pontos, das linhas, e das superfícies das coisas interiores e pesadas, "das coisas inertes que fazem cansar e adormecer, e que repousam no seio de vizinhanças permanentes, ou então mergulhadas no sono de contigüidades tão íntimas e ilimitadas, tão próximas e infinitas como se fossem os 'números surdos' de um espaço mágico constituído de sombra benfazeja e luz corrompida". Muito próximo a imagem do crivo e seu efeito no olho das rendeiras. Depois, chama atenção para o que na gravura de Goeldi é seu próprio interesse, como uma poética de um espaço de sombras, ao dizer que ela carrega o silêncio das casas desertas, da chuva, do vento, o silêncio deserto da vida, uma aceitação cordial do silêncio e do deserto da vida:

Nem tudo, porém, é noite - noite cósmica - na obra de Goeldi, mas está quase tudo inscrito numa lousa escura, tudo nos vem refletido do fundo negro de um poço, em linhas e crispamentos de luz fugidia: manhãs de pescadores, raios ardentes de meios-dias, 
caminhos abandonados, pátios de casas solitários. Em tudo há o silêncio, há um silêncio na chuva e no vento, há um "silêncio no mar", e ainda tudo é deserto; há o silêncio das casas desertas, há o silêncio deserto da vida, mas em tudo há também uma aceitação cordial, aceitação do silêncio e do deserto da vida. A sua atitude diante do mundo não é de luta e revolta, mas também não é a do vencido e desesperado.

Oswaldo Goeldi sentiu tão bem como seu amigo Alfredo Kubin a poesia das casas fechadas e dos pátios desertos, e é esta a aproximação mais sensível entre o artista alemão e o gravador brasileiro.

A questão de Joaquim Cardozo aponta em Goeldi é a sua própria: o quanto o deserto se fulgura como aquilo que não é uma imagem, que não é apenas um sentido para o sentido, mas sim também uma ambivalência no espaço da forma, como informe, como forma formante (expressão sua), como uma contingência que interfere radicalmente nas brechas de uma geografia do ser, como um crivo. O deserto, se é um espaço aberto para as oscilações das formas de linguagem, é também um espaço aberto para a aventura com a linguagem, uma imposição de uma presença na ausência do sentido para que através de uma penumbra poética, como uma política para o confim e para o comum, uma presença na ausência do ser-no-mundo. O poema, para Joaquim Cardozo, se arma como um começar no instante em que a palavra, como imagem desviante, a do crivo, se lança em sua mais dolorosa impotência e no ponto mais crítico de sua inoperância: no deserto da linguagem.

Como uma volta em torno da questão de Joaquim Cardozo, é possível pensar com Deleuze quando ele diz que no deserto não se enxerga de longe, que não se enxerga o deserto de longe, que nunca se está diante do deserto e, tampouco, se pode estar dentro dele. Deleuze lembra Cézanne, que falava da necessidade de perder-se sem referência: para pintar um campo de trigo, ficar muito próximo dele a ponto de não vê-lo mais. Perder-se sem referência é mover-se num espaço liso que por sua vez se move e faz mover um espaço estriado, o que detém a medida das coisas no mundo. Deleuze diz ainda que se pode recuar em relação às coisas, mas que não é um bom pintor aquele que recua do quadro que está pintando: "Um quadro é feito de perto, mesmo que seja visto de longe" (DELEUZE, 1997, p. 204) Assim como para o escritor, acrescenta, é possível escrever com uma memória curta, mas se presume que o leitor seja dotado de uma memória longa. Conclui dizendo então que a maneira de enxergar o deserto é "está-se nele" (DELEUZE, 1997, p. 204), e que estar nele é então uma incorporação, não como organismo ou organização, mas como intensidade; porque o deserto é um espaço nômade, sem tempo, sem memória, sem peso, sem leveza, háptico (que seria uma sobreposição do sentido, entre o tátil e o ótico, quando até mesmo o olho pode não ser apenas ótico), nem começo nem termo, aquilo que se desenha numa linha também nômade, "que nada delimita, que já não cerca contorno algum, que já não vai de um ponto a outro, mas que passa entre os pontos, que não pára de declinar da horizontal e da vertical, de desviar da diagonal mudando constantemente de direção". (DELEUZE: 1997, p. 210) 


\section{Dois}

Assim, é no primeiro poema do TRIVIUM ${ }^{1}$, Prelúdio e Elegia de uma Despedida (publicado em 1952 numa pequena edição de 100 exemplares), um longo poema dividido em três partes, que Joaquim Cardozo promove uma espessura no espaço para ao mesmo tempo provocar na linguagem uma espessura de duração; que não é o indivisível, como sugere Deleuze, mas aquilo que só se divide ao mudar de natureza a cada divisão. Daí, a imagem desviante do crivo. E isto pode ser remetido àquilo que Bergson chamou de uma "percepção pura", ou seja, "uma percepção que existe mais de direito do que de fato, aquela que teria um ser situado onde estou, vivendo como eu vivo, mas absorvido no presente, e capaz, pela eliminação da memória sob todas as suas formas, de obter da matéria uma visão ao mesmo tempo imediata e instantânea." (BERGSON: 1999, p. 32) O que Bergson aponta é que uma imagem - numa durèe - pode ser sem ser percebida, que uma imagem pode estar presente sem ser representada, e que a "distância entre estes dois termos, presença e representação, parece justamente medir o intervalo entre a própria matéria e a percepção consciente que temos dela." (BERGSON, 1999, p. 32) O fato é que para Bergson a nossa representação das coisas do universo vem do que estas coisas refletem contra a nossa liberdade, e é esse o ponto que parece interessar nesse poema de Joaquim Cardozo, como um crivo:

\section{PRELÚDIO E ELEGIA DE UMA DESPEDIDA}

\section{I}

No seio dessa noite ouvi um choro prolongado.

Pareceu-me, a princípio, que era o vento

Agitando as árvores do jardim,

Ou que eram vozes distantes, em serenata;

Mas era um pranto, um pranto tão sentido,

Tão perfeito e derramado

Como se descesse das estrelas

Como se viesse das montanhas

Como se subisse da terra fria ou da noite das águas.

Mas, por que choravam?

Tão longe eu me sentia, tão lento e ilimitado

Descendo das vertigens, das vertentes solitárias

Para a planície estagnada, deserta e comovida,

Por uma noite sem mancha;

E então, de mim ou a mim somente

Por que sabida ou revelada essa modulação de dor?

${ }^{1}$ O TRIVIUM é um livro composto de três poemas: Prelúdio e Elegia de uma Despedida, Visão do Último Trem Subindo ao Céu e Canto da Serra dos Órgãos, publicado em 1970. 
Essa névoa de angústia esgarçada na altura?

Densa lamentação fugindo sobre o vento,

Talvez aspirações de surtos e renovos,

Desejos de acender nos céus infindos

Fanais de aurora.

Cresceram, cresceram as árvores da noite,

Subiram das cavernas, dos poços e das minas,

Sobre mortas raízes renasceram, sobre pétreas raízes

$E$ as frondes elevaram além dos círculos celestes.

Em vão estendo as minhas mãos na treva

Para colher o fruto do contato imaturo,

Para alcançar a flor da exigente esperança,

Das primícias da forma o antecipado alcance

E do contorno exul a urgência da lembrança.

Em vão concentro o olhar nesse negro tecido

E busco distinguir as sombras disponíveis

Aos apelos do dia, aos êxtases da cor:

Variedades de escuro na imanência de azuis e de vermelhos, A própria, a mesma, a lídima e pressaga substância Que do opaco e do fecundo da amplidão telúrica As flores trazem em suas mãos de pétalas.

Oh! Noite de terra vegetal, de húmus e de estrume!

Em vão! Por toda a parte o vulto da recusa,

O Avesso, o Detrás, o Por baixo, o De permeio,

Multidão de velados rostos, luz voltada.

Mas há germinação nesse tranqüilo seio de negrume, Vegetação de pranto que ascende e se articula Em palavras; e floresce e frutifica e amadurece. Vozes em fim cantando; tarde finda da colheita; Vozes depois fluindo entre paisagem e caminho.

É noite! É noite! e o sono vem sobre os telhados;

Uma tropa de cavalos campolinos

Em trajetória e agitação de caudas e de crinas

Batendo as patas surdas e macias;

É noite! É noite! e o sono vem sobre os telhados.

Que linguagem há de vir desse pranto perfeito e derramado Nessa noite das noites, nessa noite sem mancha? Noite fecunda de gravitações e metamorfoses, 
De palavras repercutindo em prelúdio e despedida,

De números comprimidos entre Ínfimo e Supremo,

De música infreqüente, inconforme, nutrida

Na síncopa e no soluço de vozes infantis.

\section{II}

No seio dessa noite de turfa e de antracito

o fogo sempre a abrir em súbitas corolas

Das luzes minerais as dálias amarelas;

As dálias dos jardins de adormecidas anilinas. . .

Mas de tudo e de mim prossegue essa agonia

Em que procuro ouvir, em que busco saber

Da imensa Queda universal

- e os anjos dessa Queda?

No mundo provocando as ondas luminosas!

Eis a face sem brilho, eis a boca em silêncio

Eis o vulto sem forma, eis a forma em tumulto,

Eis o pranto a escorrer dentre as fendas noturnas,

Eis a noite - o que é bem noite e o que é mais noite -

a noite. .

a noite. .

A noite é o negro diamante, o carbonado

Abrindo no cristal as praias estelares.

E lâmpada de Korf, suspensa dos abismos,

Rompe os muros do dia, apaga o rastro da morte

$E$ de dentro da luz os náufragos retira

Como seres sepultos em profundos espelhos.

Livre expansão do olhar sobre o dia hemisférico

Exercício dos ciclos na grande feira celeste:

Ciclo das estrelas

- moscas de Azul, de Branco e de Vermelho - contra a vidraça.

Ciclo das águas

- sempre as mesmas, sempre as mesmas -

Onde nascem, onde morrem peixes sempre outros.

Ciclo das estações abafando em folhagens o coração dos homens!

Ah! ciclo do sangue nas artérias dos amantes!

Ciclo da matéria frágil, severa e obstinada!

Matéria do mundo grande,

Rosa de quatro elementos,

Rajada de quatro ventos, 
Quatro cães que estão ladrando, Quatro nuvens derramando Água, fogo, terra e ar. Ciclo - o que é dado logo após de possuído - e apenas provado é devolvido.

Ciclo - ilusão do regresso!

Se a noite é total e completa, por que não nos revela o mistério? Por que não nos integra na sua amplidão libertária? Inutilmente deixamos os nossos rastros, inutilmente cortamos na rocha [os nossos nomes

Como se marcássemos na argila do tempo as nossas pegadas Como se inscrevêssemos na cortiça da noite as curvas de nosso grito.

Sobre dínamos, turbinas e locomotivas

A inércia-primavera irromperá de novo

E uma seiva nascerá do sangue e da saliva,

Da lágrima e do leite materno,

De mel, de suor e de vinho;

Primavera onde eternamente vibrará, de nós, a ausência e o vazio.

Pois esse choro noturno e prolongado

Das estrelas - como se descesse

Da terra fria - como se subisse

E, por si mesmo, como se chorasse,

Não dará linguagem.

\section{III}

É preciso partir enquanto é noite, Enquanto é aspiração de absoluto.

É preciso voar no vórtice das lendas, das histórias antigas.

Viajar, circular, além das águas, além do ar.

Do ar - plâncton do espaço, alimento das asas.

- casulo da luz - crisálida.

A treva que desvenda e que liberta

Com seu poder noturno a pulsação não doma

Dos planetas escuros na mais densa matéria nuclear,

Nem a noite maior das negras nebulosas.

Se as coisas do mundo se encadeiam e implacáveis gravitam

Do calor das estrelas ao pesado frio derradeiro,

Por que há na infância uma doçura simples e primeva?

$E$ as cores espectrais por que se alongam 
Em ruivo e moreno, em zaino e rosilho,

E na explosão reside o acontecimento de uma flor?

Água, água de chuva

- presença unânime da Queda -

Aura da esperança; sombra do castigo;

Água pesada, água de chincho

- Água da chuva -

Chuva! Cabelos brancos, cabelos frios

Dessa noite velha, dessa noite fria

Que me apaga a vista, que me extingue a voz.

Chuva em que vou com a alma embuçada

E o coração molhado e vazio.

Ouço os teus passos ligeiros de fantasma, O teu fragor funesto, o teu rumor sombrio Chuva da eterna morte!

Se é impossível voltar e possível não é perdurar Na hora intensa da espera, no espaço da demora, É partir!

É partir e partir para o fim das memórias. . . Arcturus, Antares, Altair! Capitâneas

Dessa navegação taciturna e para sempre

E para além da verdade e grandeza da vida.

É partir e partir para o fim das idades. . .

Já a eterna luz com os seus dedos de rosa

Estende o azul do dia;

É partir e partir para além da saudade.

Das vinhas de orvalho instante da vindima,

Meandros matinais de frondes vaporosas

E os galos proclamando de próximo a longínquo, Nas úmidas distâncias, o canto da aventura.

Rio, 1952

O deserto é, assim, no poema de Joaquim Cardozo, uma possibilidade de espaço que vem nessa noite inconforme quando o universo não se divide, e abre uma possibilidade de liberação da linguagem como potência e desejo, como um começar de uma paisagem, profundamente, onde a linguagem se amalgama como uma 'questão profunda' do inexpresso da imagem, que vem do crivo. Isto 
vai comparecer por todo o TRIVIUM numa espécie de palavra-imagem, ou de palavra-contra-maquinização, que subverte o que seria o real, ou o realismo, aquilo que aparentemente funciona bem, numa escavação da experiência com a linguagem que atinge o acidente e também o mistério através de um rumor, como um gozo e um jorro de desejo para a graça, ampliando-os. Esta escavação da experiência com a linguagem feita por Joaquim Cardozo é um aberto para poder dispor do espaço de uma outra forma, que seria a da forma formante; o espaço que é o deserto - como uma quebra no tempo e uma maneira aberta de aguçar a percepção. Algo como aquilo que Bergson disse num movente da percepção, que "Todo realismo fará portanto da percepção um acidente, e por isso mesmo um mistério." (1999, p. 23) Ele acresce ainda que "a percepção dispõe do espaço na exata proporção em que a ação dispõe do tempo." (BERGSON, 1999, p. 28)

O procedimento de Joaquim Cardozo toca a suspensão da imagem para que ela possa tocar a sua assombração, como um crivo, através do deserto, através de uma liberdade do ser-no-mundo, como um canto de aventura, numa percepção que só conserva da matéria o seu fantasma: é partir e partir, diz ele. O poema cumpre a travessia de uma planície deserta, comovida, de luz mineral numa noite sem mancha, com modulações de dor e névoas de angústia, para distinguir as sombras disponíveis, como sugere: "Para alcançar a exigente flor da esperança". É um poema que insere uma duração num aprendizado para partir, a vida sempre como um curso, a partida como um morrer; como diz Maria da Paz Ribeiro Dantas: "o canto da aventura - o Prelúdio fundindo-se à Despedida, o começo prolongando-se no fim -, para daí retornar ao ponto de partida, cumprindo a viagem ao absoluto, à totalidade, já que é preciso partir enquanto é aspiração de absoluto." (DANTAS, 2003, p. 85)

\section{Três}

O poema monta um tempo circular e sem limite, aberto, confim, comum, um tempo que se move numa circunferência sem começo e sem termo e plena de elipses para as várias faces da antimatéria. Este tempo desenha pelas três partes do poema um ato de bondade para o ser-no-mundo numa aura de esperança, é um ato de bondade de um coração molhado pela água pesada da chuva, a "água de chincho": que se acumula numa planta frágil como o gravatá. A imagem se transfere no correr do poema até um coração vazio, o coração que é por onde há um outro saber, o coração-ouriço, de um ser que sabe que pode morrer. É uma arqueologia comovida que se dá numa dilatação de seu procedimento poético, até fazer com que a realidade tome o sentido deserto numa contemplação ausente e num espaçamento desse sentido deserto. No dizer de Antonio Houaiss, a poesia de Joaquim Cardozo é carregada de um tônus afetivo, melancólico, "mas de uma melancolia sábia, a melancolia do humor, a melancolia do belo aceitar da vida, mas com resignação provisória ante sua feiúra conjuntural, já que a vida era - e é, mesmo como preparação para a morte - essencialmente digna de viver-se." (HOUAISS, 1976, p. 89) O poema, então - nesta presença de um sentido ausente -, diz de um mundo anterior ao homem, de um mundo que é também fora do 
homem e que é nosso único mundo: o da revelação. Jean-Luc Nancy diz que é a este mundo que pertencemos como seres desejantes, porque o desejo é a falta e é a falta que modula a relação com o sentido. (2003, p. 74, 75 e 76)

Esta arqueologia da percepção do sentido ausente, uma imagem ausente proposta na figuração do crivo, e no deserto, está no que Lélia Coelho da Frota também chama de revelação, uma revelação das ausências: "Pelo desfolhamento da matéria, por uma arqueologia não obstante amorosa e comovida com a beleza do mundo, Joaquim Cardozo vai retirando as pedras do real para chegar à corola da revelação." (FROTA, 1979) Diz ainda que a poesia de Joaquim Cardozo implica e solicita uma meditação do transcendente, do que nos outra como iluminação e concentração de espírito: "A sua poesia, iniciada num regional sem regionalismos, alheia ao anedótico, atinge agora as notas da meditação transcendental. Tornase reduto de concentração e espírito, intelectualidade e iluminação." (FROTA, 1979) Se seguirmos Blanchot, temos o argumento que numa relação entre o pensamento e a literatura um escritor tem todos os direitos e pode atribuir-se todas as maneiras de ser e de dizer, com exceção à palavra habitual que tenha pretensão de sentido e de verdade. Que é o no 'ainda não' - como se o mundo da verdade só devesse começar amanhã, como propõe Robert Musil - que o ser pode se revelar na arte, porque este ser que se revela na arte é sempre anterior à revelação; diz ele que vem "daí a sua inocência (pois não tem que ser resgatado pela significação), mas daí a sua inquietude infinita". (MUSIL, 1994, p. 159) Assim, o comentário de Antonio Houaiss acerca de Joaquim Cardozo e do procedimento em sua poética reitera a questão, porque entre um "transitório individual" e um "transitório exemplar" para "além da verdade e grandeza da vida" (como está dito no poema acima) sobra uma ingenuidade, uma inocência e uma inquietude infinitas numa tentativa de tocar a experiência falhada do ser-no-mundo:

Desde então Joaquim Cardozo vem sendo o que fora sempre, esse poeta da dignidade humana, da fraternidade humana, que nos revelava, antes, o matizado vário da vida, com cheiro de maresia e tremores de noites estreladas ou chuvosas, enluaradas ou opacas, em que a concupiscência mesma era - e poderosa - expressão do amor e do vínculo específico de continuidade, no transitório individual, em que o localismo pernambucano era o veículo de amor telúrico para os homens de todos os outros localismos, e que nos revela, a partir de então, em despojando-se do transitório exemplar, o eterno da vocação humana - o amor, a paz, a vida, em acentos que ficarão como lapidares provas de uma personalidade rica de humanidade, porque essencialmente solidária com os homens, inconformada com a deformação da vida, a cantar a vida que deveria ter sempre sido, para ser eterna na espécie, com ser eterno no cosmos - e para além da verdade e grandeza da vida. (HOUAISS, 1976, p. 93/94)

Joaquim Cardozo transporta para seu poema, como sugere Houaiss, um corpo contínuo temporal que propõe uma ética inconformada, uma ética que rege sua postura como aquilo que ele pode e tem que ser como poeta e como homem, num movimento de passagem e transitório. Agamben, ao escrever sobre a ética, 
diz que há algo de fato que o homem é e tem de ser, "mas este algo não é uma essência, não é propriamente uma coisa: é o simples fato da sua própria existência como possibilidade ou potência." (AGAMBEN, 1993, p. 39) Se a experiência do homem moderno leva em conta que se está diante de um corpo contínuo da vida, um tempo em que um eu profundo articula experimentar alguma liberdade de ação como uma ética possível, Joaquim Cardozo refaz isto em seu poema para tentar tocar e chegar o mais perto possível daquilo a que chamamos de real. O eu profundo e trágico no poema de Joaquim Cardozo é aquilo a que estou chamando deserto, como o mais íntimo do ser, do ser-no-mundo; e da imagem do crivo, que é de onde se parte e se erma o espaço como lugar e sombra. Bergson, por sua vez, usa a imagem do cone para tentar representar o que ele chama de movimento, ou de duração do tempo, que seria para ele uma forma legítima deste eu profundo estar no mundo e na vida. Num incessante alargamento do cone, o movimento que vai do vértice para a base, que é quando as experiências presentes passam pelo inconsciente, e depois, quando saem da base para o vértice, que é quando o inconsciente emerge atuando sobre o plano da consciência, é que ele se pergunta o quanto da realidade do movimento vai até a consciência, como desejo ou sentido, enquanto ele é produzido.

A conclusão a que Bergson chega é a de que tocamos a realidade do movimento quando ele nos aparece, em nosso interior, como uma mudança de estado ou qualidade. A duração do movimento decompondo-se em momentos espaciais, como o da experiência interior, ou do eu profundo, é a linha de trajeto que interessa a Bergson. Ele fala de uma continuidade movente. E afirma que "estabelecer relações muito particulares entre porções assim recortadas da realidade sensível é justamente o que chamamos viver". (BERGSON, 1999, p. 233) O viver é, para ele, um movimento, uma duração, como uma força entre átomos, como uma matéria, um corpo, que não se define pela solidez, mas provavelmente por um estado fluido da ação livre, uma ética. Como se um fluido perfeito, contínuo, homogêneo e incompreensível que preenche o espaço, o tempo, com sua individualidade, seu movimento. O que Bergson tenta é estreitar a ligação existente entre tempo, espaço e experiência e coloca, sub-repticiamente, como potência, um eu profundo interior como ponto de partida para a experiência, para o que podemos chamar de começo, começar. O que está se impondo como um começar, agora, no poema de Joaquim Cardozo é um espaço de demora, uma mora ampliada, suspensa, intervalada. Ou seja, um começar que possa tocar através do "infinito possível da poesia" (LIMA, 1996, p. 203) o descentramento de alguma imagem no espaço, para ermar o espaço, para tornar-se ela mesma espaço.

\section{Bibliografia:}

AGAMBEN, Giorgio. A comunidade que vem. Trad. António Guerreiro. Lisboa: Presença, 1993.

BERGSON, Henri. Matéria e Memória. Ensaio Sobre a Relação do Corpo com Espírito. São Paulo: Martins Fontes, 1999. 
CARDOZO, Joaquim. Para Todos: Rio de Janeiro, São Paulo, v. 1, n. 11, p. 9, 2a quinz. out. 1956.

DANTAS, Maria da Paz Ribeiro. Joaquim Cardozo - Contemporâneo do Futuro. Recife: Ensol, 2003.

DELEUZE, Gilles. Mil Platôs - Capitalismo e Esquizofrenia - 5. Trad. Peter Pál Pelbart e Janice Caiafa. São Paulo: 34, 1997.

FROTA, Lélia Coelho. Sombra e claridade em Joaquim Cardozo. Cultura, Brasília, v. 8, n. 31, p. 63, jan./mar. 1979.

HOUAISS, Antônio. Seis poetas e um problema. Rio de Janeiro: MEC, 1960.

LIMA, José Lezama. A dignidade da poesia. Trad. Josely Vianna Baptista. São Paulo, Ática, 1996.

NANCY, Jean-Luc. El sentido del mundo. Trad. Jorge Manuel Casas. Buenos Aires: La Marca, 2003.

\section{Abstract:}

The article shows how Joaquim Cardozo works the poem through the idea of language as a deviant image, open, from the image of the crivo, to achieve its own desert. The article comes from Joaquim Cardozo's critical thought and from a poem called "Prelúdio e Elegia de uma Despedida", first published in 1952, in a book called TRIVIUM, to verify the relations of his poetry with that matter.

\section{Keywords:}

Poem, desert, place, experience, Joaquim Cardozo. 